\title{
A risky political game with climate change
}

\author{
Mehdi Mirsaeidi ${ }^{1}$, Abdy Javadzadeh ${ }^{2}$ and Michael Campos ${ }^{1}$ \\ Affiliations: ${ }^{1}$ Division of Pulmonary and Critical Care, University of Miami, Miami, FL, USA. ${ }^{2}$ Dept of Sociology \\ and Anthropology, Florida International University, FL, USA.
}

Correspondence: Mehdi Mirsaeidi, Division of Pulmonary and Critical Care, University of Miami, 1600 NW 10th Ave \# 7060A, Miami, FL 33136, USA. E-mail: msm249amed.miami.edu

$@$ ERSpublications

The health effects of climate change are serious challenges for physicians, scientists and politicians http://ow.ly/ym2h30evYa4

Cite this article as: Mirsaeidi M, Javadzadeh A, Campos M. A risky political game with climate change. Eur Respir J 2017; 50: 1701145 [https://doi.org/10.1183/13993003.01145-2017].

Phrases and words such as "climate change", "global warming", "greenhouse effect", "depletion of the ozone layer", "rising sea levels" and "carbon footprint" have become part of the popular vernacular; household names, in a manner of speaking. We are all, to varying degrees, familiar with the viewpoints and ideas behind these concepts, and have had time to absorb and react to them. The way most of us have reacted can be gauged on a continuum. At one extreme, there are those who demonstrate a great deal of concern, and take personal, social, environmental and sometimes political action to correct a man-made phenomenon, and on the other side, there are those who do not care or pay much attention because they do not feel that climate change is really happening or is a direct effect of human action on Earth. In between, there are those who believe that climate change is a real phenomenon but that it will correct by itself. Physicians, biologists, and environmental and social scientists, as well as some politicians at local, state and federal levels, are the ones paying the highest attention to this ongoing environmental disaster. Unfortunately, despite ample and strong evidence about the reality of this issue, there are still those in positions of authority who live oblivious to the real magnitude of this problem.

In 2005, the Paris Agreement was signed by 197 governments around the globe to unify policies to fight climate change and achieve climate neutrality before the end of the century [1]. Under this agreement, participating governments from nearly the entire world agreed to set a long-term temperature goal of holding the global average temperature increase to well below $2^{\circ} \mathrm{C}$, and to pursue efforts to limit this to $1.5^{\circ} \mathrm{C}$ above pre-industrial levels by reducing carbon dioxide emissions. Bringing together so many governments to accede on an environmental issue at the global level was unprecedented. However, on March 28, 2017, the current US administration issued an executive order to eliminate the Clean Power Plan policy, and the regulations on methane and other volatile organic compounds, two policies aimed to combat anthropogenic climate change. The Clean Power Plan requires electricity generating plants in the USA to reduce carbon dioxide output by $32 \%$ by the year 2030 [2]. This new executive order is likely to hamper the US capacity to meet its emissions commitments under the 2015 Paris agreement [3].

The scientific evidence supporting the assertion that climate change is driven by industrialism and anthropogenic increases in atmospheric greenhouse gases is undeniable. Carbon dioxide is a potent greenhouse gas, and plays a vital role in regulating the Earth's surface temperature and radiative forcing that leads to the greenhouse effect. According to the US National Aeronautics and Space Administration,

Received: June 072017 | Accepted after revision: July 092017

Conflict of interest: Disclosures can be found alongside this article at erj.ersjournals.com

Copyright OERS 2017 
the current raising warming trend is extremely likely to be (with $>95 \%$ probability) the result of human activity since the mid-20th century [4]. The World Health Organization has estimated that annual deaths attributable to climate change is growing and will reach up to 250000 a year by 2050 [5]. The elderly, pregnant women, children, and people with pre-existing pulmonary and cardiac conditions are particularly vulnerable to the immediate potential health effects related to climate change, and the entire population is at serious risk of infectious and noninfectious diseases that result from the climate change [6].

As climate change directly affects the epidemiology of several infections by affecting the life cycle of vectors, the geographic distribution of several infectious agents and diseases, including tick-borne diseases, malaria, endemic fungal infections and foodborne diseases, are closely related to local environmental changes [7]. Changes in the epidemiology of respiratory infections, particularly avian influenza, has also been linked to climate change [8]. In addition, lung health can be affected by climate-related changes in air pollution levels, in particular with increases in particles with diameter $<2.5 \mu \mathrm{m}$, which are known to be associated with important respiratory effects and increased mortality [9]. Ozone, a powerful oxidant, is predicated to increase due to the mix of anthropogenic emissions and rising temperatures. Ground-level ozone pollution has been associated with increased frequency of asthma and chronic obstructive pulmonary disease exacerbations [10]. Climate change also impacts on agriculture and food supply by leading to extended periods of dry weather and water supply due to a lack of rain or snow. Consequently, climate change plays a big role in driving people to migrate [11]. Immigration is a well-known critical factor for outbreaks of emerging infectious diseases or changes in the prevalence of infections such as tuberculosis [12]. This can result in global spread of airborne infectious diseases.

The existing process of climate change is still preventable and, hence, reversible. To meet the current challenge, we can apply what we have learned from our last environmental change, the global action against chlorofluorocarbons (CFCs). CFCs are synthetic, halogenated alkanes that used to be installed in refrigerators and contribute to ozone depletion by photolytic processes in the stratosphere [13]. In 1987, the production of CFCs was restricted by a strong international collaboration and commitment called the Montreal Protocol. The success of the Montreal Protocol agreement has been tested several times with showing declining in the concentrations of CFCs in atmosphere years later [14].

The Paris Protocol will be another successful international agreement if members, including the US government, stay committed to decreasing carbon dioxide emissions and replacing fossil fuels with clean energy. Expanding clean energy would ease fuel shortages and ecological threats. It would also generate new technologies and creates thousands of new jobs. To prevent irrevocable damage to the environment in the next decades, we need to act now, with fervour. We should urgently make improvements, and alter the attitude and practice on climate change in our nation and possibly worldwide.

The US government, at the local and federal level, should respond positively to this threat, activate the Clean Power Plan and stay committed to the Paris agreement. US industry should be regulated to reduce greenhouse gases, as current regulation is only partial, including only cars, light trucks and stationary sources of greenhouse gases. There should be plans to widen regulations to include punitive and stricter standards for new power plants. Finally, we should consider that the health effects of climate change may be beyond our ability to adapt to the environmental stress, and consequently, the human race may be faced with the most serious risk of extinction.

\section{Acknowledgements}

M. Mirsaeidi conceived this editorial and performed the literature review. M. Mirsaeidi, A. Javadzadeh and M. Campos wrote the article or had substantial involvement in its revision before submission. The guarantor of this article is M. Mirsaeidi

\section{References}

1 United Nations Framework Convention on Climate Change. The Paris Agreement. http://unfccc.int/paris agreement/items/9485.php Date last accessed: May 25, 2017. Date last updated: June 20, 2017.

2 The White House. Presidential executive order on promoting energy independence and economic growth. www. whitehouse.gov/the-press-office/2017/03/28/presidential-executive-order-promoting-energy-independence-andeconomi-1 Date last accessed: May 25, 2017. Date last updated: March 28, 2017.

3 Sarfaty M. High risk US policy on climate change. BMJ 2017; 357: j1735.

4 National Aeronautics and Space Administration. Global Climate Change: Vital Signs of the Planet. Climate change: how do we know? https://climate.nasa.gov/evidence/ Date last accessed: May 25, 2017. Date last updated: August 15, 2017.

5 The World Health Organization. Climate change and health. www.who.int/mediacentre/factsheets/fs266/en/ Date last accessed: May 25, 2017. Date last updated: July 2017.

6 Ayres JG, Forsberg B, Annesi-Maesano I, et al. Climate change and respiratory disease: European Respiratory Society position statement. Eur Respir J 2009; 34: 295-302.

7 Dobson A. Climate variability, global change, immunity, and the dynamics of infectious diseases. Ecology 2009; 90 : 920-927. 
8 Mirsaeidi M, Motahari H, Taghizadeh Khamesi M, et al. Climate change and respiratory infections. Ann Am Thorac Soc 2016; 13: 1223-1230.

9 D’Amato G, Cecchi L, D’Amato M, et al. Climate change and respiratory diseases. Eur Respir Rev 2014; 23: $161-169$.

10 D'Amato G, Vitale C, De Martino A, et al. Effects on asthma and respiratory allergy of climate change and air pollution. Multidiscip Respir Med 2015; 10: 39.

11 McMichael C, Barnett J, McMichael AJ. An ill wind? Climate change, migration, and health. Environ Health Perspect 2012; 120: 646-654.

12 Barnett ED, Walker PF. Role of immigrants and migrants in emerging infectious diseases. Med Clin North Am 2008; 92: 1447-1458.

13 Molina MJ, Rowland FS. Stratospheric sink for chlorofluoromethanes - chlorine atom catalyzed destruction of ozone. B Am Meteorol Soc 1974; 55: 491-491.

14 Qin DJ. Decline in the concentrations of chlorofluorocarbons (CFC-11, CFC-12 and CFC-113) in an urban area of Beijing, China. Atmos Environ 2007; 41: 8424-8430. 